\title{
The Surface Structure of Electrodeposited Nickel
}

\author{
By Koji Hashimoto*
}

\begin{abstract}
The crystal structure of electrodeposited nickel with a preferred orientation was investigated by electron microscopy and electron diffraction. A number of twins occurred frequently in all of the deposits having (100), (110), (210) and (211) preferred orientations, respectively. Particularly in those with the (211) orientation, twin pyramids of a two-fold symmetry with a twin plane perpendicular to the substrate surface were observed. An extra diffraction spot arising from deposits with the (211) orientation has been considered to be due to a hexagonal close-packed phase of nickel or cobalt coexisting with a face-centered cubic phase. However, since the extra spot arises from the effect of kinematical double diffraction at boundaries between matrix and twin, the previous interpretation of this extra spot in terms of the presence of a hexagonal close-packed metal is not justifiable. It was considered that in the above four preferred orientations the deposits would not be chemically stable and there is no great difference in chemical activity among the deposits with different preferred orientations.
\end{abstract}

(Received April 14, 1965)

\section{Introduction}

Finch et al. (1) (2) reported that the structure of electrodeposited metals was profoundly affected by that of the substrates in early stages of electrodeposition, and with the increase of thickness the deposits showed characteristic preferred orientations independent of the substrate. There have been many reports ${ }^{(3)},{ }^{(4)}$ that preferred orientations depend on electrolytic conditions such the as composition of solution, $\mathrm{pH}$, current density, temperature, additives and stirring, and the preferred orientations of $(100),(110),(210)$ and $(211)+(10 \overline{1} 0)_{h \cdot c \cdot p}$ occur according to the electrolytic conditions. The author ${ }^{(5)}$ investigated the effect of the crystal structure on the chemical activity of an electrodeposited nickel, and found that twinning dislocations and twin boundaries are chemically most active because of their initial dissolution in a corrosive solution.

Many workers(3)(4) (6) (7) reported that a small quantity of a hexagonal phase was formed only in an electrodeposited f.c.c. nickel with the (211) preferred orientation. According to Yang ${ }^{(6)}$, the hydrogen content of the deposits mixed with the hexagonal structure was much higher than that of the deposits having a simple f.c.c. structure : It is likely, therefore, that the mobility of metal atoms was seriously impeded by hydrogen existing on the cathode surface, or the stress was developed in the deposits owing to the occlusion of large amounts of hydrogen, so that the mixed structure of h.c.p. and f.c.c. phases occurred. Reddy ${ }^{(7)}$ suggested that the deposits which had been considered to be the h.c.p. nickel might consist of the cobalt phase, because the

* The Research Institute for Iron, Steel and Other Metals, Tohoku University, Sendai, Japan.

(1) G. I. Finch and C.H.Sun : Trans. Faraday Soc., 32(1936)852

(2) G.I. Finch and A.L.Williams: Trans. Faraday Soc., 33 (1.1937), 564.

(3) B. C. Baner jee and A. Goswami : J. Electrochem. Soc., 106 (1959), 20. ibid, 590.

(4) H. Okada, I. Takamura and T. Ishida : Bull. Uuiv. Osaka Prefecture, (1959), 83.

(5) K. Hashimoto : Trans. JIM, 4 (1963), 142.

(6) L. Yang : J. Elect rochem. Soc., 97 (1950), 241.

(7) A. K. N. Reddy : Acta Cryst., 17 (1964), 443. lattice constant of the h.c.p. nickel was the same as that of the h.c.p. cobalt and the co-deposition of cobalt was accelerated by conditions under which the h.c.p. nickel was deposited.

In view of the facts that the hexagonal nickel with the $(10 \overline{1} 0)_{h \cdot c . p .}$ orientation was not observed in any other deposits except those having the $(211)_{f \cdot c \cdot c \cdot}$ orientation and that the observations were made only by reflection electron diffraction, there remains a question as to the existance of the hexagonal nickel in the deposits.

In the present study, the surface structure of electrodeposited nickel with various orientations was investigated in detail, and the possibility of the existence of the hexagonal phase was discussed.

\section{Experimental Procedure}

In a preliminary experiment in which a chemically polished copper sample was used as the substrate, the orientation of the deposits was not reproducible. In order to obtain a good reproducibility of the orientation by keeping the surface condition of the substrate constant, mechanically polished copper disks were used as cathodes. The composition and $\mathrm{pH}$ of the electrolytic solution are shown in Table 1. The $\mathrm{pH}$ value was

Table 1 Composition and $\mathrm{pH}$ of electrolytic solutions.

\begin{tabular}{c|ll|l|l|ll}
\hline & \multicolumn{1}{|c|}{$\mathrm{A}$} & \multicolumn{1}{|c|}{$\mathrm{B}$} & \multicolumn{1}{|c|}{$\mathrm{C}$} & \multicolumn{2}{c}{$\mathrm{D}$} \\
\hline $\mathrm{NiSO}_{4} \cdot 7 \mathrm{H}_{2} \mathrm{O}$ & 1 & $\mathrm{M} / 1$ & $0.82 \mathrm{M} / 1$ & $0.82 \mathrm{M} / 1$ & 0 & $\mathrm{M} / 1$ \\
$\mathrm{NiCl}_{2} \cdot 6 \mathrm{H}_{2} \mathrm{O}$ & 0 & & 0.18 & 0.18 & 1 & \\
$\mathrm{H}_{3} \mathrm{BO}_{3}$ & 0.48 & 0.48 & 0.48 & 0.48 \\
$\mathrm{pH}$ & 4 & 4 & 5 & 4 \\
\hline
\end{tabular}

adjusted by the addition of a $\mathrm{NaOH}$ aqueous solution. The current density employed was 47 or $31 \mathrm{~mA} / \mathrm{cm}^{2}$ and the solutions were unstirred. The thickness of the deposits ranged from about 5 to about $15 \mu$. In the examination of the surface structre of the deposits, electron microscopy using acetyl cellouse carbon replicas and reflection electron diffraction were adopted. An electron microscope HU-11 type was used for electron 
microscopy and electron diffraction, the acceleration voltage being 75 and $10 \mathrm{kV}$, respectively.

\section{Results and Discussion}

Electron diffraction studies revealed that the polycrystalline deposits, which showed initially a random orientation, developed preferred orientations depending on the composition and $\mathrm{pH}$.of electrolytic solutions and the current densities, as the thickness increased. The relation between them is given in Table 2 .

Electron diffraction patterns from the deposits having these preferred orientations are shown in Photos. $1 \sim 4$. Twin spots appeared in the patterns of the (100) (Photo. $1)$ and (210) (Photo. 3) orientations, but they were not

Table 2 Preffered orientation of electrodeposited Nickel.

\begin{tabular}{c|c|c}
\hline $\begin{array}{c}\text { Elect rolytic } \\
\text { solution }\end{array}$ & $\begin{array}{c}\text { Current density } \\
\mathrm{mA} / \mathrm{cm}^{2}\end{array}$ & Orientation \\
\hline A & 47 & $(110)$ \\
\hline B & 47 & $(210)+$ Twin spots \\
\hline C & 47 & $(210)+$ Twin spots \\
\hline D & 31 & $(100)+$ Twin spots \\
\hline
\end{tabular}

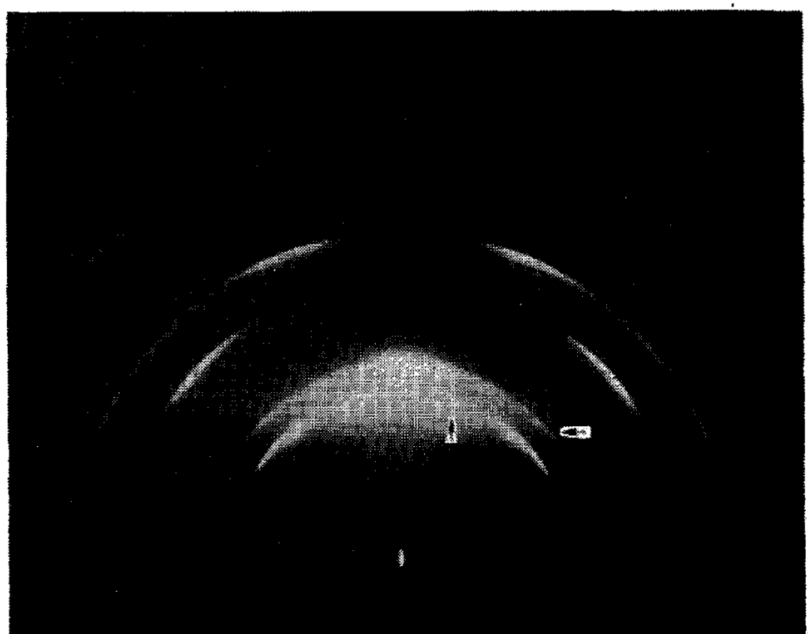

Photo. 1 Electron diffraction pattern of (100) deposits. Twin spots are indicated by arrows.

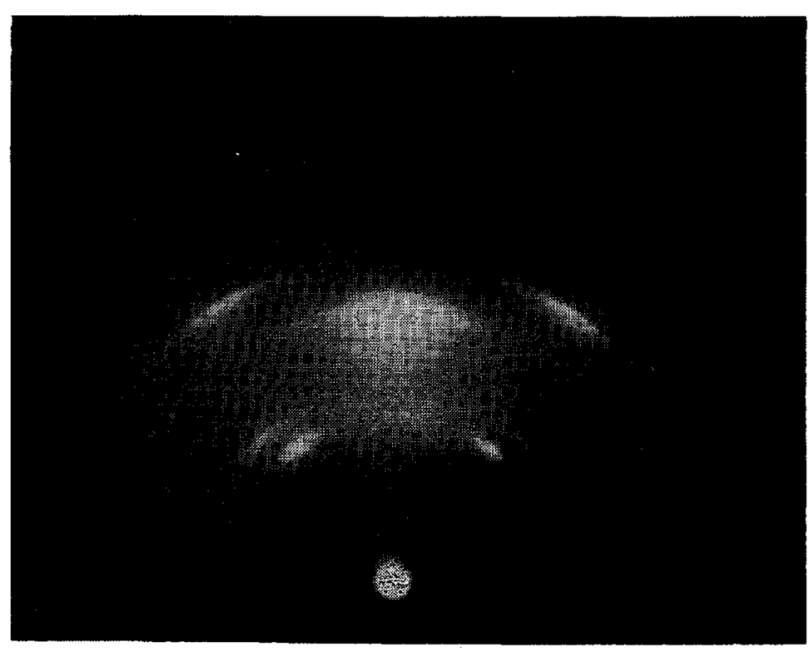

Photo. 2 Electron diffraction pattern of (110) deposits. observed in those of the (110) (Photo. 2) and (211) (Photo. 4) orientations. In the (211) orientation, an extra spot which could not be expected from the matrix and twins appeared*. This extra spot has so far been interpreted in terms of the (10) 0 ) reflection due to the

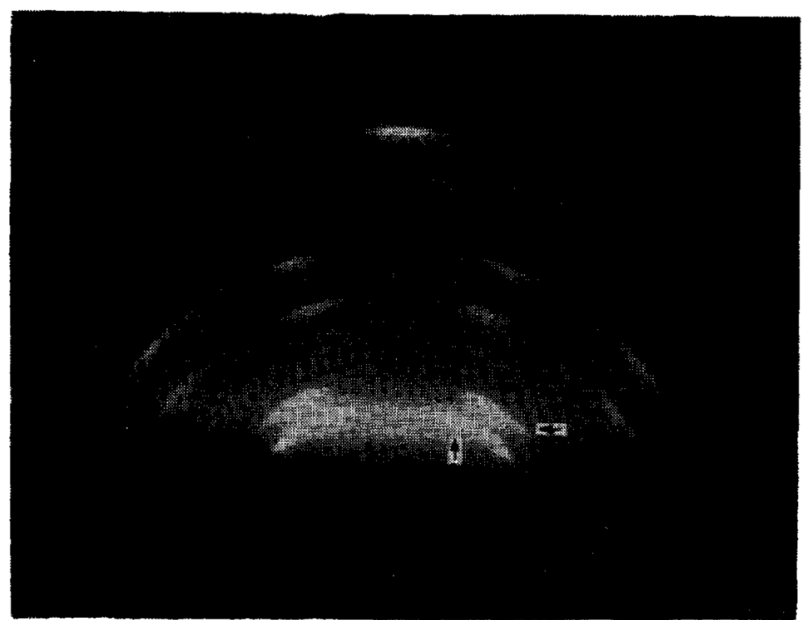

Photo. 3 Electron diffraction pattern of (210) deposits. Diffuse rings of oxide also appear. Twin spots are indicated by arrows.

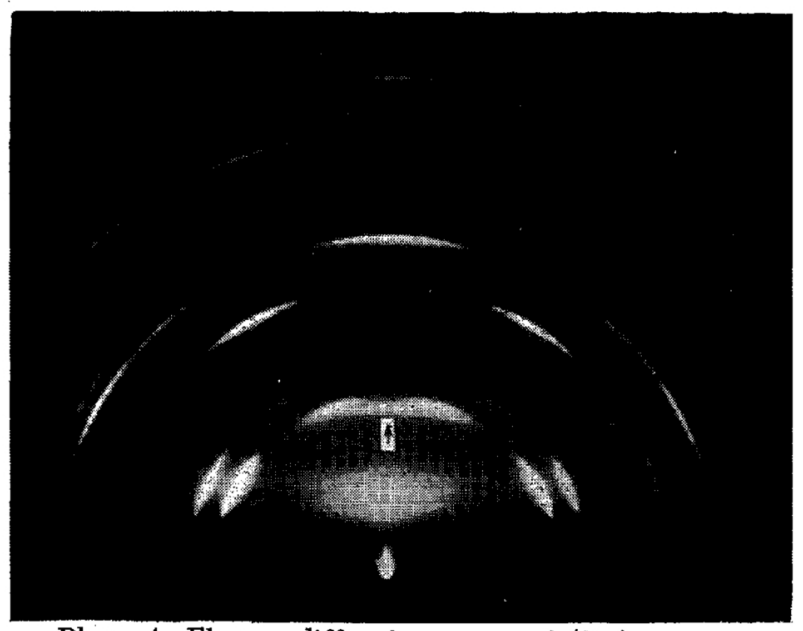

Photo. 4 Electron diffraction pattern of (211) deposits. The extra spot is indicated by an arrow.

hexagonal phase contained in the deposited nickel.

The surface structures of electrodeposited crystals are shown in Photos. 5 7. In the $(210)$ orientation lowhillocks are densely distributed and in the (110) orientaion relatively large hillocks are sparsely observed. In the (211) orientation pyramids consisting of four planes occur frequently and have a plane with a two-fold symmetry perpendicular to the surface of deposits.

It was found from the electron diffraction patterns of the four orientations that crystallites have preferred axes perpendicular to the surface and take a random orientation within the surface. The reciprocal lattice of deposited crystals, therefore, rotates about the axis perpendicular to the surface, and if the Ewald Sphere is approximated by a plane, the reciprocal lattice points on this plane are given in Figs. $1 \sim 4$ for the four orientations, respectively.

\footnotetext{
* In the present paper, one kind of the twinned crystals is
} called the matrix and the other the twin, 
When an f.c.c. crystal is twinned on all the four $\{111\}$ planes, the reciprocal lattice points of the twin components can be obtained from the matrix reciprocal lattice by a rotation of $180^{\circ}$ about a $\langle 111\rangle$ twin axes. An $(h k l)_{z}$ plane of a crystal which is twinned on an $(H K L)$ plane is transformed to $\left(h^{\prime} k^{\prime} l^{\prime}\right)_{\mathrm{T}}$ in the matrix lattice by the following equation ${ }^{(8)}$ :

$$
\left(h^{\prime} k^{\prime} l^{\prime}\right)_{\mathrm{T}}=(h k l)_{\mathrm{Z}}-\frac{2\left(h_{\mathrm{Z}} H+k_{\mathrm{Z}} K+l_{\mathrm{Z}} L\right)}{H^{2}+K^{2}+L^{2}}(H K L) .
$$

Using this equation, all of the twin lattice points indexed by $\{111\},\{200\}$ and $\{220\}$ were transformed into indices of matrices. These reciprocal lattice points also rotate about the orientation axis perpendicular to the deposit surface according to the four preferred orientations. These twin points are shown in Tables $3 \sim$ 6 and in Figs. 1 4. The indices in each Table are those of the spots which should appear in the electron diffraction pattern obtained from the $\{111\}$ twinned lattices of the orientaion.

Table 3 Twin spots expected to appear in the $(100)$ orientation.

\begin{tabular}{|c|c|c|c|c|c|}
\hline$(\boldsymbol{H} K L)$ & 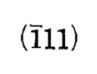 & $\langle(1 \overline{1} 1\rangle$ & (111) & (111) & $\begin{array}{l}\text { Symbole } \\
\text { in Fig. } 1\end{array}$ \\
\hline $\begin{array}{l}\text { The angle bet ween } \\
\text { the }(H K L) \text { and } \\
(100) \text { planes }\end{array}$ & $54^{\circ} 44^{\prime}$ & $54^{\circ} 44^{\prime}$ & $54^{\circ} 44^{\prime}$ & $54^{\circ} 44^{\prime}$ & \\
\hline$(h k l)_{z}$ & $\begin{array}{l}(111) \\
(111) \\
(111) \\
(020) \\
(002) \\
(200) \\
(022) \\
(220) \\
(202)\end{array}$ & $\begin{array}{l}(11 \overline{1}) \\
(111 \overline{1}) \\
(111) \\
(002) \\
(200) \\
(02 \overline{2}) \\
(200) \\
(20 \overline{2})\end{array}$ & $\begin{array}{l}(1 \overline{1} \overline{1}) \\
(11 \overline{1}) \\
(1 \overline{1} 1) \\
(020) \\
(00 \overline{2}) \\
(200) \\
(0 \overline{2} \overline{2}) \\
(\overline{2} 20) \\
(20 \overline{2})\end{array}$ & $\begin{array}{l}(1 \overline{1} 1) \\
(111) \\
(1 \overline{1} \overline{1}) \\
(00 \overline{2}) \\
(020) \\
(200) \\
(022) \\
(202) \\
(2020)\end{array}$ & $\begin{array}{l}\mathbf{T}_{1} \\
\mathbf{T}_{2} \\
\mathbf{T}_{3} \\
\mathbf{T}_{4} \\
\mathbf{T}_{5} \\
\mathbf{T}_{6}\end{array}$ \\
\hline
\end{tabular}

Table 4 Twin spots expect ed to appear in the (110) orientation.

\begin{tabular}{|c|c|c|c|c|c|}
\hline$(\boldsymbol{H K L} \boldsymbol{L})$ & $(\overline{1} 11)$ & (11̄1) & (111) & (111) & $\begin{array}{l}\text { Symbole } \\
\text { in Fig.2 }\end{array}$ \\
\hline $\begin{array}{l}\text { The anlge bet ween } \\
\text { the }(H K L) \text { and } \\
\text { (110) planes }\end{array}$ & $90^{\circ}$ & $90^{\circ}$ & $35^{\circ} 16^{\prime}$ & $35^{\circ} 16^{\prime}$ & \\
\hline$(h k l)_{z}$ & $\begin{array}{c}(111) \\
(11 \overline{\mathbf{1}}) \\
= \\
\overline{-} \\
(200) \\
(020) \\
(20 \overline{2}) \\
(022) \\
= \\
= \\
= \\
= \\
=\end{array}$ & $\begin{array}{l}(111) \\
(11 \overline{1}) \\
= \\
\overline{\bar{y}} \\
(200) \\
(020) \\
(02 \overline{2}) \\
(202) \\
= \\
= \\
= \\
= \\
=\end{array}$ & $\begin{array}{c}\bar{z} \\
(11 \overline{1}) \\
(1 \overline{1} \overline{1}) \\
(\overline{1} 1 \overline{1}) \\
= \\
= \\
\overline{\bar{c}} \\
(00 \overline{2}) \\
(\overline{2} 00) \\
(0 \overline{20}) \\
(\overline{20} \overline{2}) \\
(0 \overline{2} \overline{2}) \\
(\overline{220} 0)\end{array}$ & $\begin{array}{c}\overline{-} \\
(111) \\
(\overline{1111}) \\
(\overline{11} 1) \\
= \\
= \\
\overline{-} \\
(002) \\
(200) \\
(020) \\
(\overline{20} 02) \\
(022) \\
(220)\end{array}$ & $\begin{array}{r}\mathrm{M}_{1} \\
\mathrm{X} \\
\mathrm{X} \\
\mathrm{M}_{2} \\
\mathrm{M}_{3} \\
\mathrm{X} \\
\mathrm{X} \\
\mathrm{X} \\
\mathrm{X}\end{array}$ \\
\hline
\end{tabular}

\section{The $(\mathbf{1 0 0})$ orientation}

For the deposits of the (100) orientation, the reciprocal lattice points of twins described in Table 3 should appear in positions of $\mathrm{T}_{1}$ to $\mathrm{T}_{6}$ as shown in Fig. 1 . These are found in the electron diffraction pattern of Photo. 1. The angles between the four $\{111\}$ twin planes and the (100) deposit surface are all $54^{\circ} 44^{\prime}$. Deposited crystals twinned on the four twin planes

(8) H. Schlötterer : Z. Naturforsch., 17 A (1962), 355. oblique to the surface are developed, and some of the crystals may have a twin relation to each other. Since twin planes were not single, the surface of deposits showed complex shapes of hillocks similar to those of the (210) orientation shown in Photo. 5.

Table 5 Twin spots expected to appear in the $(210)$ orientation.

\begin{tabular}{|c|c|c|c|c|c|}
\hline$(\boldsymbol{H} \boldsymbol{K} \boldsymbol{L})$ & (111) & $(1 \overline{1} 1)$ & (111) & $(\mathbf{1 1} \overline{1})$ & $\begin{array}{l}\text { Symbole } \\
\text { in Fig. }\end{array}$ \\
\hline $\begin{array}{l}\text { The angle bet ween } \\
\text { the }(H K L) \text { and } \\
\text { (210) planes }\end{array}$ & $75^{\circ} 02^{\prime}$ & $75^{\circ} 02^{\prime}$ & $39^{\circ} 14^{\prime}$ & $39^{\circ} 14^{\prime}$ & \\
\hline$(h k l)_{\mathrm{z}}$ & $\begin{array}{c}(111) \\
(11 \overline{1}) \\
(1 \overline{1}) \\
= \\
(\overrightarrow{020)} \\
(200) \\
(002) \\
- \\
\overline{-} \\
(022) \\
(20 \overline{2}) \\
(\overline{2} 20) \\
- \\
- \\
-\end{array}$ & $\begin{array}{c}(11 \overline{1}) \\
(11 \overline{1}) \\
(1 \overline{1} \overline{1}) \\
= \\
- \\
-\cdot \\
(020) \\
(200) \\
(00 \overline{2}) \\
- \\
\overline{-} \\
(02 \overline{2}) \\
(202) \\
(\overline{2} 20) \\
- \\
- \\
-\end{array}$ & 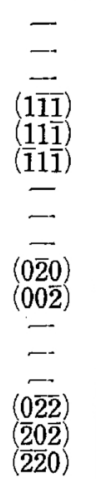 & $\begin{array}{c}- \\
z \\
\overline{-} \\
(\overline{1} 11) \\
(\overline{111}) \\
(\overline{1} 11) \\
\overline{-} \\
\overline{-} \\
(\overline{0 \overline{2} 0}) \\
(002) \\
- \\
\overline{-} \\
(\overline{0} \overline{2} 2) \\
(\overline{2} 02) \\
(\overline{2} 20)\end{array}$ & $\begin{array}{l}\mathbf{T}_{1} \\
\mathbf{T}_{2} \\
\overrightarrow{\mathbf{M}_{1}} \\
\mathbf{M}_{2} \\
\mathbf{T}_{3} \\
\mathrm{~T}_{4} \\
\mathrm{~T}_{5} \\
\overline{-} \\
\overline{\mathrm{T}_{6}} \\
\mathbf{T}_{7} \\
= \\
= \\
=\end{array}$ \\
\hline
\end{tabular}

Table 6 Twin spots expected to appear in the (211) orientation.

\begin{tabular}{|c|c|c|c|c|c|}
\hline$(\boldsymbol{H} K L)$ & (1111) & (1̄11) & (111̄) & (111) & $\begin{array}{l}\text { Symbole } \\
\text { in Fig.4 }\end{array}$ \\
\hline $\begin{array}{l}\text { The angle bet ween } \\
\text { the }(H K L) \text { and } \\
\text { (210) planes }\end{array}$ & $90^{\circ}$ & $61^{\circ} 52^{\prime}$ & $61^{\circ} 52^{\prime}$ & $19^{\circ} 28^{\prime}$ & \\
\hline$(h k l)_{\mathrm{z}}$ & $\begin{array}{c}(111) \\
(111) \\
(111) \\
= \\
= \\
\bar{\Xi} \\
(002) \\
(020) \\
(200) \\
= \\
= \\
= \\
(022) \\
(220) \\
(20 \overline{2}) \\
= \\
= \\
= \\
=\end{array}$ & 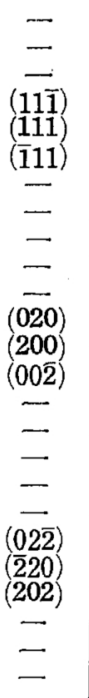 & 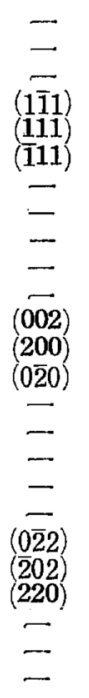 & 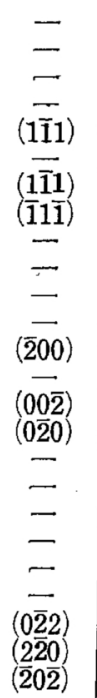 & $\begin{array}{l}\mathrm{M}_{1} \\
\mathrm{M}_{2} \\
\mathrm{X} \\
\mathbf{X} \\
\mathbf{X} \\
\mathrm{X} \\
\mathrm{M}_{3} \\
\mathrm{M}_{4} \\
\mathbf{X} \\
\mathbf{X} \\
\mathrm{X} \\
\mathrm{X} \\
\mathrm{M}_{5} \\
\mathrm{M}_{6} \\
\mathrm{X} \\
\mathrm{X} \\
\mathrm{X} \\
\mathrm{X} \\
\mathrm{X} \\
\mathrm{X}\end{array}$ \\
\hline
\end{tabular}

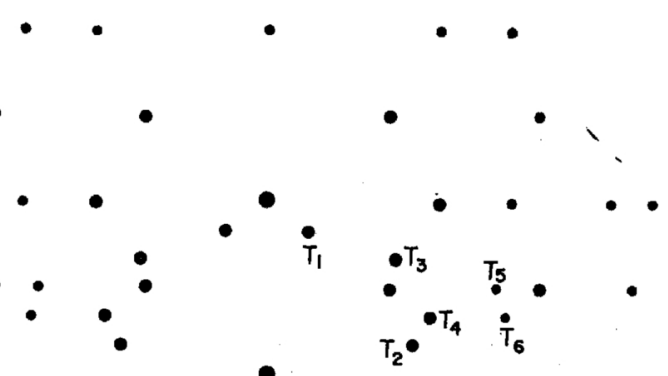

Fig. 1 Reciprocal lattice points of the matrix having the $(100)$ orientation and the twin.

The points of crystals twinned on all four $\{111\}$ planes are indicated by $T_{1}-T_{6}$. 


\section{The $(110)$ orientation}

Comparison of Photo. 2 with Fig. 2 and Table 4 indicates that diffraction spots of crystals twinned on (111) and $(11 \overline{1})$ planes were not observed in the dif-

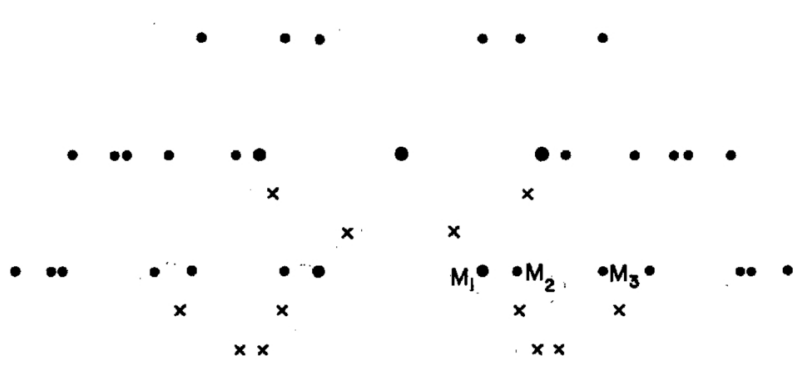

Fig. 2 Reciprocal lattice points of the matrix having the (110) orientation and the twin.

Crosses show the points of crystals twinned on (111) and (11) planes which do not appear in Photo.2. Superposed points of the matrix and the twin are indicated by $\mathbf{M}_{1}-\mathbf{M}_{3}$
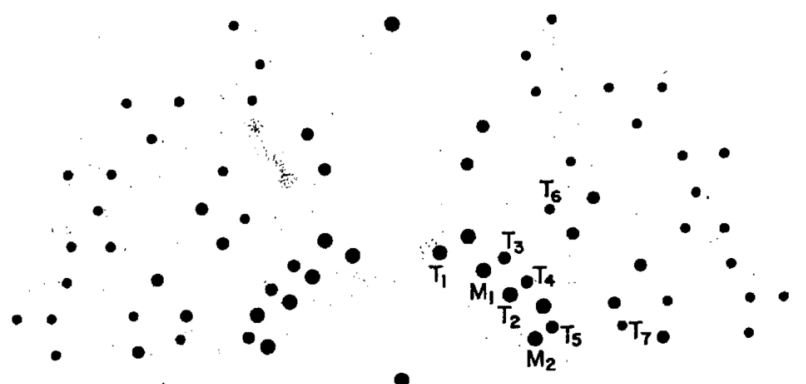

Fig. 3 Reciprocal lattice points of the matrix having the (210) orientation and the twin.

$\mathrm{T}_{1}-\mathrm{T}_{6}$ show the points of crystals $t$ winned on (111) and (111) planes. $M_{1}$ and $M_{2}$ are the superposed points of the matrix and the crystal twinned on (111) and (111) planes.

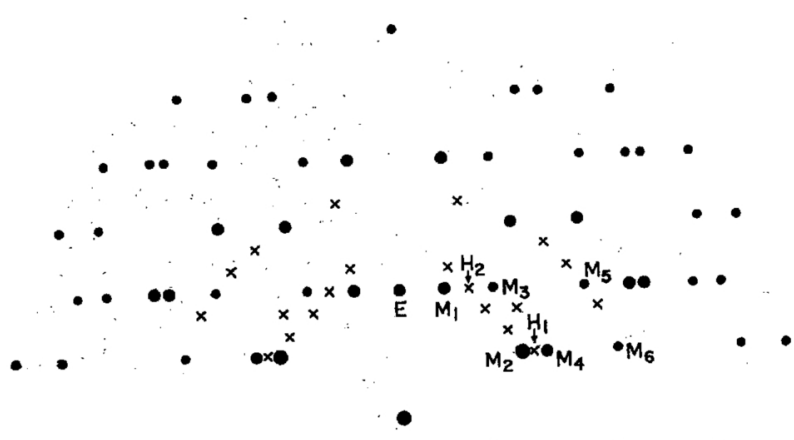

Fig. 4 Reciprocal lattice points of the matrix having the (211) orjentation, the twin and the hexagonal phases. $\mathbf{M}_{1}-\mathbf{M}_{6}$ show the superposed points of the matrix and the crystals twinned on (111) plane. Crosses are the points of crystals twinned on (1111), (11) and (111) planes and of hexagonal phase indicated by $\mathrm{H}_{1}$ and $\mathrm{H}_{2}$. These points do not appear in Photo.2.

fraction pattern of the (110) orientation. The angles between these two $\{111\}$ planes and the surface are both $35^{\circ} 16^{\prime}$, and crystals twinned on these planes making a relatively small angle with the surface did not occur. The other two $\{111\}$ planes, (III) and (1II) planes, make the right angle with the surface plane, and twins may occur on these planes making the largest angle with the surface. However, the twinning on these planes could not be confirmed, because this twinning does not produce any reflections other than those from the matrix, as indicated by $M_{1}$ to $M_{3}$ in Fig. 2 .

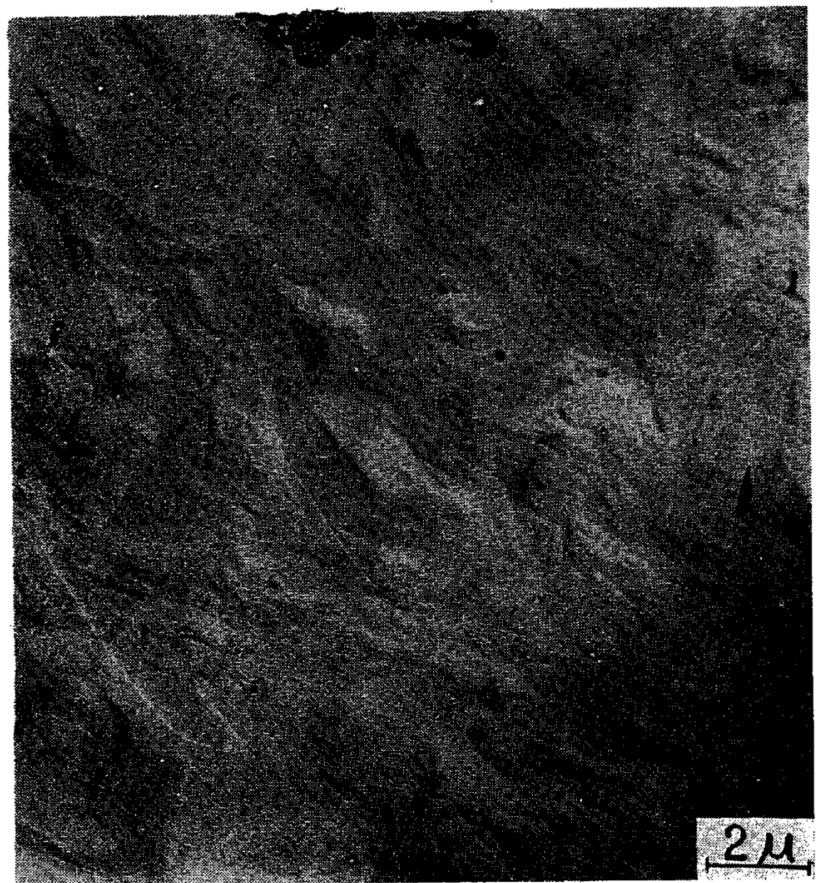

Photo. 5 Electron micrograph of (1.10) deposits.

In the electron micrograph of this orientation as shown in Photo. 5, hillocks with flat planes oblique to the surface are observed, although the density is low. According to Schlötterer ${ }^{(9)}$, pyramids having a nearly five-fold symmetry which resulted from successive

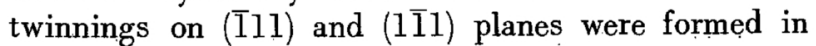
deposits of this orientation. In the present study, the hillocks were observed, but pyramids with a nearely five-fold symmetry did not occur. It appears that crystals twinned on either of the two $\{111\}$ planes perpendicular to the surface might begin to grow. However, the effect of kinematical double diffraction which will be mentioned in case of the (211) orientation was not observed, because these twinned crystals were low in hight and low in density.

\section{The $(210)$ orientation}

The twin spots of crystals twinned on (I11) and (1II) planes shown in Table 5 appear in the elctron diffraction pattern of Photo. 3 , corresponding to the points indicated by $\mathrm{T}_{1}$ to $\mathrm{T}_{7}$ in Fig. 3 . Whereas, those of crystals twinned on (111) and (11) planes cannot be confirmed because of superposition of them on matrix spots as indicated by $\mathrm{M}_{1}$ and $\mathrm{M}_{2}$ in Fig. 3. The (I11) and $(1 \overline{1} 1)$ planes makes an angle of $75^{\circ} 02^{\prime}$ with the deposit surface which is parallel to the (210) plane, and the (111) and (11̄) planes makes an angle of $39^{\circ} 14^{\prime}$. Twinning on the (111) and (11) planes making a smaller angle with the deposit surface seems not to occur, as in case of the (110) orientation. It is probable that the hillocks observed in Photo. 6 were form-

(9) H.Schlötterer : Z. Kristallogr., 119 (1964), 321 
ed by crystals twinned on the (III) and (1III) planes, and electrons reflected by some hillocks gave rise to the matrix spots, and those reflected by the others brought about the twin spots in the electron diffraction pattern. Therefore, some hillocks in Photo. 6 correspond to the matrixes and the others to the twins.

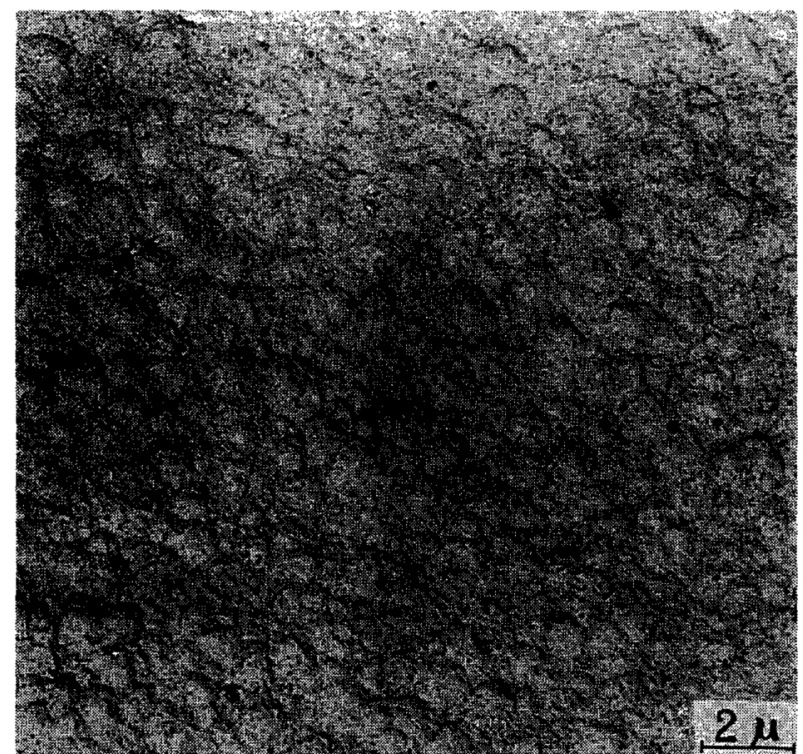

Photo. 6 Electron micrograph of (210) deposits.

\section{The $(211)$ orientation}

Twin points from crystals twinned on (1II), (11) $)$ and (111) planes listed in Table 6 are indicated by crosses in Fig. 4, but not observed in the electron diffraction

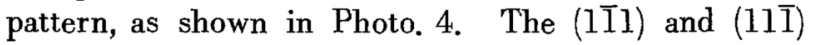
planes make an angle of $61^{\circ} 52^{\prime}$ with the (211) plane, and the (111) plane makes an angle of $19^{\circ} 28^{\prime}$. It is impossible, as in cases of the (110) and (210) orientations, that twinning on the (111) plane occurs, because the angle between (111) and (211) planes is very small.

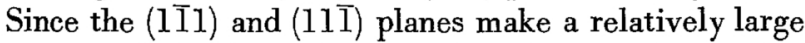
angle with the (211) plane, on the other hand, twinning on these planes appears to occur. However, as will be mentioned in the following paragraphs, crystals twinned on the (I11) plane making the right angle with the (211) plane covered the deposit surface (Photo. 7), so that no space was afforded for the occurrence of crystals twinned on the (III) and (III) planes.

Since all of the twin spots from crystals twinned on the (I11) plane, listed in Table 6 , are superposed on those from the matrix indicated by $M_{1}$ to $M_{6}$ in Fig. 4 , the twinning on this plane cannot be confirmed. In the electron diffraction pattern of deposits having the (211) orientation (Photo. 4) an extra irrational spot which could not be expected either from the matrices from twins, took place as indicted by $\mathrm{E}$ in Fig. 4 . This spot corresponds to the $1 / 3(422)$ reflection has been believed to be due to the the hexagonal phase having the (1010) orientation, which consists of nickell deposited ${ }^{(3),(4),(6)}$ or cobalt contained within nickel salts as an impurity and co-deposited ${ }^{(7)}$.

The h.c.p. phase $(a=2.492, c=4.069 \AA)$ of nickel or cobalt has the $[10 \overline{10}]$ direction as a fibrous axis perpendicular to the deposit surface, making its reciprocal lattice points rotate about this axis. Therefore, some of the reciprocal lattice points corresponding to the h.c.p. phase are entered in Fig. 4 by symbols of $\mathrm{E}, \mathrm{H}_{1}$ and $\mathrm{H}_{2}$. Intensities diffracted from the h.c.p. lattice were calculated from the multiplicity factore $(M)$, the atomic scattering factor $(f(\theta))$ of nickel for electrons ${ }^{(10)}$

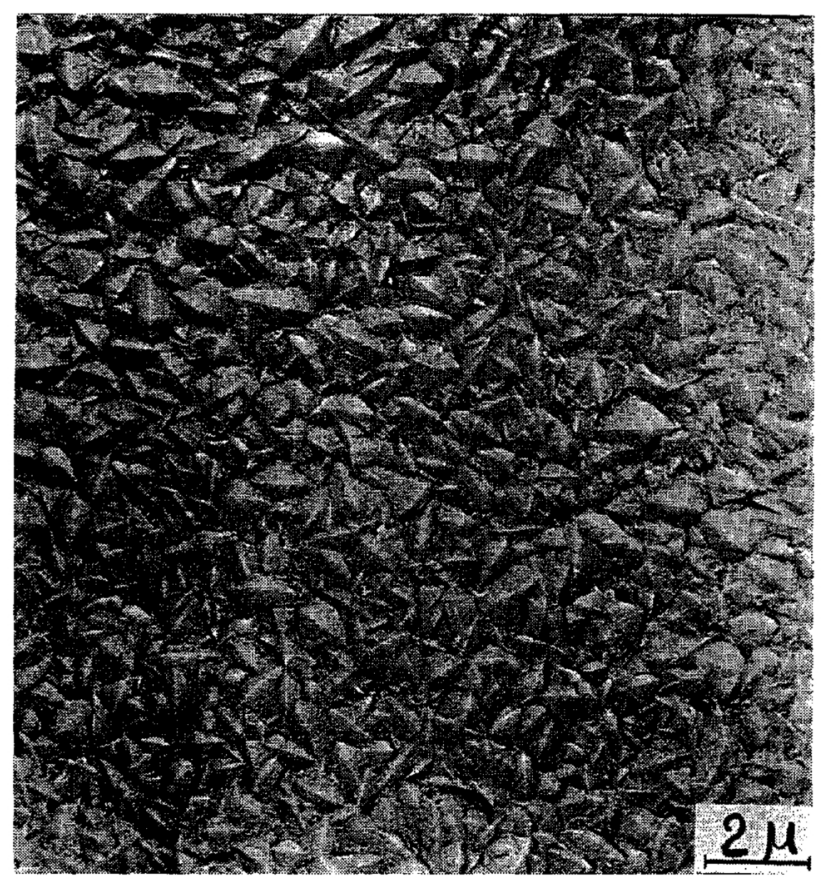

Photo. 7 Electron micrograph of $(211)$ deposits.

and the factor of rotation of reciplocal lattice points, as shown in Table 7. If the extra spot $\mathrm{E}$ in the (211) orientation results from the h.c.p. phase of nickel or cobalt with the $(10 \overline{1} 0)$ orientation, all of the spots in Table 7 must appear, because the other spots are stronger than $\mathrm{E}$, and particularly the intensity of the spot indicated by $\mathrm{H}_{1}((01 \overline{\mathrm{I}} 1),(10 \overline{1})$ and $(01 \overline{1} \overline{1}))$ in Fig. 4 is more than two and half times as large as that of $\mathrm{E}$ (1010). The spot corresponding to $\mathrm{H}_{1}$, however, is not observed at all in the electron diffraction pattern of Photo. 4. Consequently, it is not considered that the

Table 7 Diffraction intensity from the h.c.p. phase of the $(10 \overline{1} 0)$ orientation.

\begin{tabular}{|c|c|c|c|c|}
\hline$(h k l)$ & $f(\mathbf{O})^{*}$ & I† & $\mathrm{I} / \mathrm{IH}_{1}$ & $\begin{array}{l}\text { Symbole in } \\
\text { Fig. } 4\end{array}$ \\
\hline$(10 \underline{1} \mathbf{1} 0)$ & 3.09 & 9.55 & 39.9 & $\mathbf{E}$ \\
\hline $\begin{array}{l}(01 \overline{1} 0) \\
(1 \overline{1} 00)\end{array}$ & 3.09 & 7.67 & 32.0 & \\
\hline$(0002)$ & 2.94 & 22.66 & 94.6 & \\
\hline$(10 \overline{1} 1)$ & 2.79 & 15.29 & 63.4 & $\mathrm{H}_{2}$ \\
\hline$(101 \overline{1} 1)$ & 2.79 & 23.95 & 100 & $\mathrm{H}_{1}$ \\
\hline
\end{tabular}

* Atomic scattering amplitude for electrons

$\dagger$ Diffraction intensity calculated by the following equation $\mathbf{I}=\mathbf{M}|\mathbf{F}| 2 / \cos \sigma \sin \tau$

where $M$ is the multiplicity factor of reciprocal lattice points, $F$ the structure amplitude for electrons and the denominator the factor resulting from the rotation of reciprocal lattice points. The diffraction intensity of $(10 \overline{1} 0)$ is calculated by $I=M|F|^{2}$, because this point is on the fibrous axis and is not affected by the rotation.

(10) G. Thomas : Transmission Electron Microscopy of Metals, John Wiley \& Sons, 1962 p. 287. 
extra spot $\mathrm{E}$ results from the $h_{i} c . p$. phase of nickel or cobalt having the (10I0) orientation.

It was reported by Pashley and Stowell(11), who studied evaporated gold films by transmission electron microscopy and diffraction, that extra rings previously interpreted as arising from the h.c.p. metal could be explained by double diffraction at twin boundaries. In the (211) orientation of electrodeposited nickel, the (I11) plane makes the right angle with the deposit surface, and the twinning on this plane would occur. When the twin plane is the $(\bar{I} 11)$ plane, the $(1 \bar{I} 1)_{z}$ and $(11 \overline{1})_{z}$ planes give rise to a spot in the same position as the matrix spot $\mathrm{M}_{2}\left((\overline{\mathrm{I}} 11)_{\mathrm{M}},(\overline{\mathrm{I}} \mathrm{l})_{\mathrm{M}}\right)$ in Fig. 4 , and the indices of these planes are transformed into the indices of the matrix lattice by the equation (1) as follows :

$$
(1 \overline{1} 1)_{Z}=1 / 3(1 \overline{1} 5)_{\mathrm{T}} \quad \text { and } \quad(11 \overline{1})_{\mathrm{Z}}=1 / 3(15 \overline{1})_{\mathrm{T}}
$$

If the pyramid with a two-fold symmetry results from the twinning on the (i11) plane perpendicular to the deposit surface, and the electron beam is diffracted from this crystal, it is probable that the beam diffracted from the matrix passes into the twin and undergoes a secondary diffraction, or vice versa. When a kinematical double diffraction occur from the matrix $(11 \overline{1})_{M}$ or $1 \overline{1} 1)_{M}$ planes and the twin $(1 \overline{1} 1)_{z}$ or $(11 \overline{1})_{z}$ plane, the direction of the doubly diffracted beam is determined by adding the corresponding reciprocal lattice vectors :

$$
\begin{aligned}
& (11 \overline{1})_{\mathrm{M}}+1 / 3(1 \overline{1} 5)_{\mathrm{T}}=1 / 3(422) \\
& (1 \bar{I} 1)_{\mathrm{M}}+1 / 3(15 \overline{1})_{\mathrm{TT}}=1 / 3(422) .
\end{aligned}
$$

In both cases the $1 / 3(422)$ spot occurs. Consequently, it is probable that the extra spot having the index of $1 / 3$ (422) is caused by double diffraction from the crystal which is twinned on the (1111) plane perpendicular to the deposit surface. This conclusion is in good agreement with that obtained independently by Schlötterer ${ }^{(9)}$. The surface having this orientation was covered by pyramids with a two-fold symmetry perpendicular to the (211) plane, and this surface structure is consistent with the prediction from the results of electron diffraction.

It is concluded from the above that the extra spot in the $(211)$ orientation did not result from the hexagonal phase, but arose from the effect of the kinematical double diffraction. Thus, in spits of the absence of twin spots, twinning occurrs on the (111) plane.

Because of the preferred orientation and the characteristic surface structure, such a large number of double diffraction spots as observed by Pashley et al. did not appear in the present study. Decrease of the mobility of metal atoms by hydrogen existing on the cathode surface or induction of the stress by hydrogen occlusion was suggested by $Y_{a n g}{ }^{(6)}$, but they do not result in the occurrence of the mixed structure of h.c.p. and f.c.c. phases, although such circumstances may play a role in changing the preferred orientation of deposits.

Twinned crystals occurred frequently in deposits ha-

(11) D. W. Pashley and M. J. Stowell : Phil. Mag., 8 (1963), 1605. ving the (100), (210) or (211) orientations, and there is also much possibility of the occurrence of twins in the (110) orientation. According to the author's results ${ }^{(5)}$, twinning dislocations and twin boundaries were chemically most active in an electrodeposited nickel, and therefore a large number of chemically active places may exist in the deposits, and there may be no great difference in the chemical activity between the deposits having different preferred orientations.

\section{Conclusion}

The surface structure of nickel electrodeposited on copper was investigated by reflection electron diffraction and electron microscopy, and the following conclusions can be drawn.

(1) The characteristic preferred orientations with planes of low order indices parallel to the substrate surface appeared in electrodeposits, crystallites being rotated about the normal of the surface.

(2) The twinning on $\{111\}$ planes which made relatively large angles with the deposit surface occurred often in deposits.

(3) In the (100) orientation, a large number of crystals twinned on all four $\{111\}$ planes occurred.

(4) It is possible in the (110) orientation that crystals twinned on either (I11) or (III) plane may develop. Pyramids with a nearly fivefold, symmetry consisting of succesive twins on these two $\{111\}$ planes were not found.

(5) In the (210) orientation, crystals twinned on the (I11) or (1II) plane which protruded obliquely from the deposit surface occurred frequently and twins on the other $\{111\}$ planes were not observed.

(6) The surface of deposits having the (211) orientation was covered by pyramids with a two-fold symmetry, twinned on the (111) plane.

(7) The extra irrational spot in the electron diffraction pattern of deposits having the (211) orientation was previously interpreted as caused by the presence of the h.c.p. phase of nickel or cobalt, but the present study made clear that it resulted from the effect of kinematical double diffraction from the matrix and twin forming the pyramidal crystal.

(8) There may by no great difference in the chemical activity between the deposits having different orientations, probably because the twin formation is similar among different orientations.

\section{Acknowledgements}

The author wishes to express his deep appreciation to Professor Saburo Shimodaira and Professor Shiro Ogawa of The Research Institute for Iron, Steel and Other Metals, Tohoku University, Sendai, Japan, for their continuous encouragement and advice. He also wishes to thank Mr. Sadae Yamaguchi and Mr. Satoru Fujime of the same Institute for their valuable discussion during this investigation. 